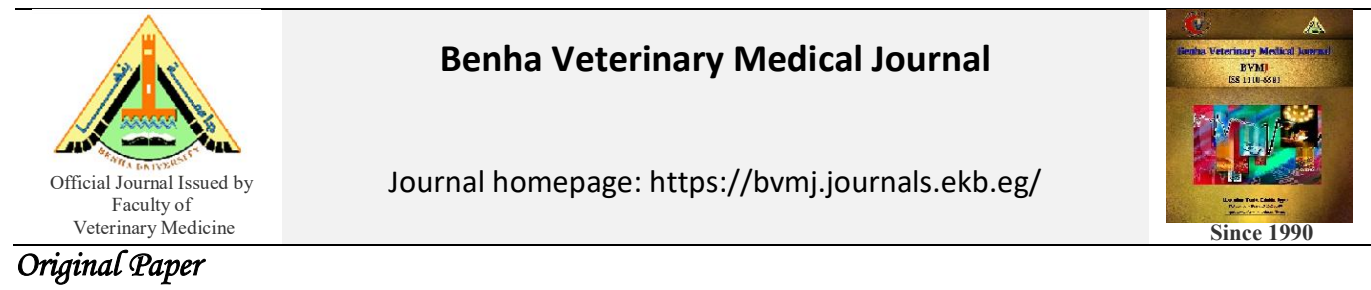

\title{
The efficacy of both locally prepared vaccines against foot and mouth disease in cattle in
} Monofeia governorate

\author{
Ehab F. Shaban', Faysal K. Ibrahim², Rania Abo-Sakaya2 *, Sayed A. H. Salem \\ ${ }^{1}$ Directorate of Veterinary Medicine, Monofeia. \\ ${ }^{2}$ Animal Medicine department ‘Faculty of Veterinary Medicine, Benha University. \\ ${ }^{3}$ Virology Department ‘Animal Health Research Institute, Dokki, Giza
}

\begin{tabular}{|c|c|}
\hline ARTICLE INFO & ABSTRACT \\
\hline $\begin{array}{l}\text { Keywords } \\
\text { Cattle } \\
F M D V \\
\text { NSP } \\
\text { ELISA kit } \\
\text { MPV } \\
\text { Received 25/03/2021 } \\
\text { Accepted 30/03/2021 } \\
\text { Availa6le On-Line } \\
01 / 07 / 2021\end{array}$ & 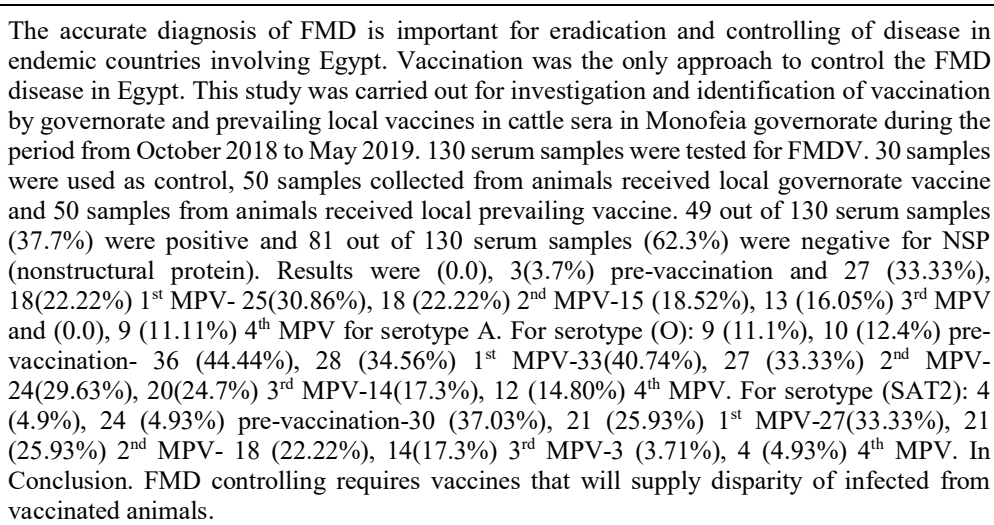 \\
\hline
\end{tabular}

\section{INTRODUCTION}

Foot and mouth disease (FMD) is an important transboundary disease that upsets cloven-footed animals in Africa and Asia Sobhy et al (2018). FMD virus include seven separate strains (A, O, C, Asia-1, and South African territories [SAT] 1-3) also numerous subtypes reflecting substantial inherited inconsistency in each serotype (Ferris et al 2009). Foot and mouth disease virus serovars $\mathrm{O}$, A and Asia-1 -1 are responsible for FMD epidemics in the Middle East and serotypes $\mathrm{O}$ and $\mathrm{A}$ are commonly spread in North Africa (Knowles et al 2012). In Egypt from 1964 to 2005, only serotype O was recognized, however in 2006, FMDV serotype A outbreak was occurred in cattle and FMDV serotype (A) was recognized as A/Egy/2006 and this strain has in excess of $90 \%$ nucleotide distinctiveness with $\mathrm{A} / \mathrm{KEN} / 98, \mathrm{~A} / \mathrm{ETH} / 92$, and $\mathrm{A} / \mathrm{KEN} / 05$, and all topotypes are closely associated. It is though overview in Egypt from East Africa was perhaps during imported live cattle from Ethiopia (through sea-route) Ahmed et al (2012). Serovars O, A and SAT-2 strains were renowned in this country since 2013 (Sobhy et al 2018). FMDV strains O, A, and SAT-2 were commonly affecting buffalos and cattle in different Egyptian governorates at a period in the summer of 2017. FMDV is transboundary from neighbor countries or thorough the importation of carrier animals (Zeedan et al 2020).

* Corresponding author: rania.aboskayah@fvtm.bu.edu.eg
The current study planned to detect the protection of different local vaccines used in Egypt filed by detection of antibody titers in serum samples collected from cattle in Monofeia governorate during the years of 2018 and 2019.

\section{MATERIAL AND METHODS}

\subsection{Serum samples:}

one hundred and sixty sera were obtained from periodically vaccinated cattle from Monofeia Governorate and used for screening of FMD nonstructural protein antibodies using ID Screen ${ }^{\circledR}$ FMD NSP Competition ELISA test and detection of antibody titers for serotypes (O, A and SAT2) by FMDV serotyping ELISA KITS. The Serum samples collected from vaccinated and non-vaccinated animals as follow:

1. Fifty serum samples were collected from cattle received governorate local vaccine and 15 serum samples were used as unvaccinated control.

2. Fifty serum samples were collected from cattle received prevailing local vaccine and 15 serum samples were used as control.

2.2. The vaccination trial (types of viral vaccines):

1. Local governorate FMD vaccine Polyvalent inactivated FMD vaccine Batch No. 1702. Exp. date 08/2019, It includes:

Inactivated FMD virus serotype A/EGY/1+2012(A Iran05) 106 TCID50 per dose 
Inactivated FMD virus serotype O/EGY-4-2012(O Panasia2) 106 TCID50 per dose

Inactivated FMD virus serotype SAT2 EGY-A-2012) (Sat 2) 106 TCID50 per dose

The vaccine is water in oil emulsion and is given $3 \mathrm{ml} /$ dose subcutaneous.

2. Locally prevailing produced Vaccine used TriAphthovac ${ }^{\circledR}$ contained A Iran05, O Pan Asia2 and SAT-2 Egypt serotypes Batch No. 1706080201. Vaccine with oil adjuvant and is given $2 \mathrm{ml} /$ dose subcutaneous.

\subsection{ELISA Kits:}

2.3.1. ID Screen ${ }^{\circledR}$ FMD NSP Competition ELISA kit: 2.3.2. Solid-phase competitive ELISA (SPCE) for antibodies against FMDV serovars $\mathrm{O}, \mathrm{A}$ and SAT 2:

Calculation of results

Inhibition $\%=100-\left(\right.$ serum OD $/$ reference OD $\left.{ }^{*}\right) \times 100$

${ }^{*}$ Reference OD $=$ mean OD of 4 wells handled with the negative Control

2.4. Preparation of collected samples:

All samples were prepared according to (OIE, 2012).

\section{RESULTS}

3.1. Seroprevalence of FMDv non-structural protein antibodies:

3.1.1 Demonstration of nonstructural protein antibodies in cattle sera pre inoculation with local governorate and local prevailing vaccines. 49 out of 130 serum samples (37.7\%) were positive and 81 out of $130(62.3 \%)$ were negative for NSP as shown in Figure (1).

3.1.2 Demonstration of non-structural protein antibodies in Monofeia governorate in October 2018 in cattle vaccinated by inactivated prevailing local vaccine:

8 out of $30(26.6 \%)$ were positive and 22 out of $30(73.4 \%)$ were negative for NSP as shown in Figure (1).

3.2. Demonstration of specific FMDv antibodies in cattle pre and post vaccination with governorate local and prevailing local vaccines:

3.2.1 Demonstration of specific antibodies in cattle sera prevaccination

The serotyping of FMD antibodies in animals received local governorate vaccine, antibodies were $9(11.1 \%)$ and 4 (4.9\%) for FMD serotype O and SAT2 respectively, while animals received prevailing local vaccine, antibodies were $3(3.7 \%), 10(12.4 \%)$ and $24(4.93 \%)$ for FMD serotype A, $\mathrm{O}$ and SAT2 respectively Figure (2).

3.2.2 Demonstration of specific antibodies in cattle sera $1^{\text {st }}$ month post vaccination:

In animals received local governorate vaccine, antibodies were $27(33.33 \%), 36(44.44 \%)$ and $30(37.03 \%)$, while animals received prevailing local vaccine, antibodies were $18(22.22 \%), 28(34.56 \%)$ and $21(25.93 \%)$ for FMD serotype A, O and SAT2 respectively Figure (2).

3.2.3 Demonstration of specific antibodies in cattle sera $2^{\text {nd }}$ month post vaccination:

In animals received local governorate vaccine, antibodies were $25(30.86 \%), 33(40.74 \%)$ and $27(33.33 \%)$, while animals received prevailing local vaccine, antibodies were $18(22.22 \%), 27(33.33 \%)$ and $21(25.93 \%)$ for FMD serotype A, $\mathrm{O}$ and SAT2 respectively Figure (2).

3.2.4 Demonstration of specific antibodies in cattle sera $3^{\text {rd }}$ month post vaccination:

In animals received local governorate vaccine, antibodies were $15(18.52 \%), 24(29.63 \%)$ and $18(22.22 \%)$, while animals received prevailing local vaccine, antibodies were $13(16.05 \%), 20(24.7 \%)$ and $14(17.3 \%)$ for FMD serotype A, O and SAT2 respectively Figure (2)

3.2.5 Demonstration of specific antibodies in cattle sera $4^{\text {th }}$ month post vaccination:

In animals received local governorate vaccine, antibodies were $14(17.3 \%)$ and $3(3.71 \%)$ for FMD serotype $O$ and SAT2 respectively, while animals received prevailing local vaccine, antibodies were 9(11.11\%), $12(14.80 \%)$ and $4(4.93 \%)$ for FMD serotype A, O and SAT2 respectively Figure (2).

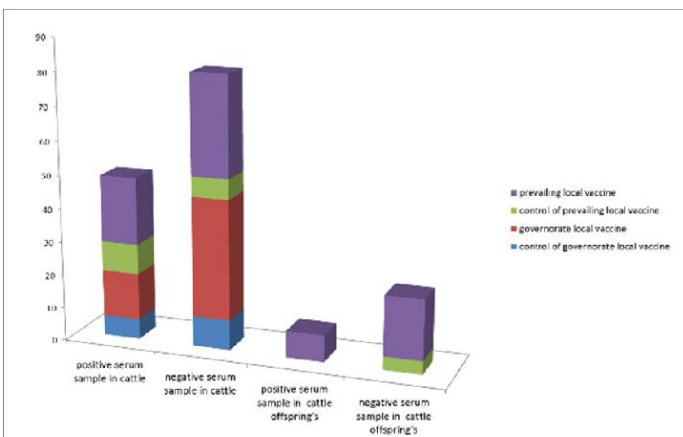

Figure 1 ID Screen ${ }^{\circledR}$ FMD NSP Competition ELISA to detect FMDV nonstructural protein antibodies in cattle and their offspring's sera pre inoculation with local governorate and local prevailing vaccines.

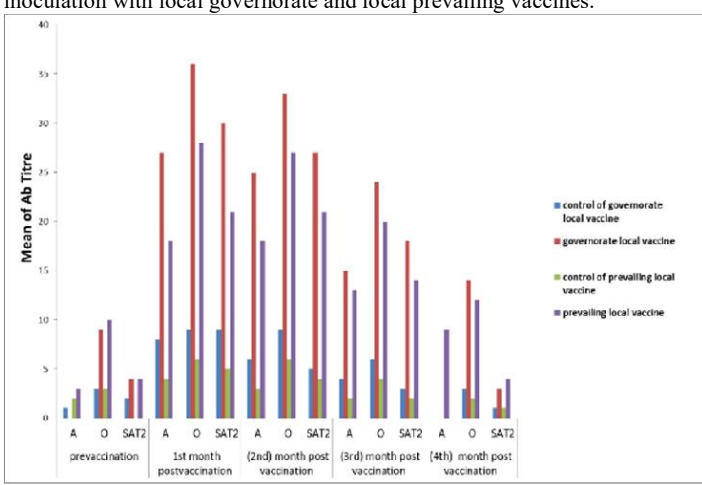

Figure 2 Mean antibodies titer in vaccinated cattle with governorate local and prevailing local vaccines by ELISA

\section{DISCUSSION}

For accurate control programs, the demonstration of the serotype complicated in field epidemics has to be recognized within laboratories. ELISA test is faster but less variable, quantitative results and is not dependent on cell-culture capabilities. The application of NSP tests after vaccination of animals is dependent on using purified, inactivated vaccine that is free (as much as is possible) of NSPs. Differentiation of diseased and immunized animals is essential for suitable eradication of FMD by vaccination and improvement of transporter animals due to immunization (Uttenthal et al., 2010).

We used ID Screen ${ }^{R}$ FMD NSP Competition ELISA kit for the discovery of FMDv non-structural protein (NSP) 
antibodies in serum obtained from cattle and their offspring's for differentiation of infected from immunized animals. Antibody reaction against FMD viral non-structural proteins was extensively used for this aim. Our results shown in Figure (1), were agreed with those of Lamya et al., (2017) who detected (37.7\%) antibodies against FMD NSP in cattle sera. Also, Raof et al., (2011) documented $27.1 \%$ in cattle and $35.7 \%$ in buffaloes. Moreover, these results agreed with kitching, (2002) and Hiam, (2005) mentioned that animals that have improved from natural infection will gain antibodies against NSP result from the virus replication in the tissue, these proteins will be expressed and encourage the creation of host specific antibodies. The recognition of antibodies can be used to identify FMD infected animals which may still loud live virus.

Our results were approved with that of Brocchi et al., (2006) reported that FMDv nonstructural protein have conventional substantial care in recent years, with exploration to improve serological tests for FMDV. Our results disagreed with those of El Daous et al., (2016) who detected (56.67\%) antibodies against FMD NSP in cattle sera.

Our result in Figure 2 were agreed with Lamya et al., (2017) who stated that cattle received polyvalent inactivated FMD vaccine, (governorate local vaccine), antibodies were $(24.2 \%),(29.5 \%)$ and $(16.1 \%) 2$ WPV for FMD serotype A, $\mathrm{O}$ and SAT2, respectively. The results agreed with results obtained by El-Bagoury et al., (2014). Animals may be persistently infected with FMD after challenge with live FMD virus. Inactivated FMD virus vaccine persuades structural proteins antibodies only. (Clavijo et al., 2004). Inactivated FMD vaccines are vital component for control and eradication policies both in endemic and free areas (Valarcher et al., 2008).

Abd El-Rhman et al., (2020) was used solid-phase competitive ELISA, which indicate the circulation of serovars $\mathrm{O}, \mathrm{A}$, and SAT2 between cattle as 52.2, 17.4, and $30.4 \%$, respectively, while buffaloes were $31.8 \%, 27.3 \%$, and $40.9 \%$, respectively. These results are agreed with Diab et al., (2019) who identified the same 3 serotypes between cattle. Abd El-Rhman et al. (2015) Who stated that, serotype "O" was commonly isolated from cattle and buffaloes in Egypt. Strain "O" responsible for in excess of $60 \%$ of the FMD epidemics worldwide. Mahapatra, and Parida, (2018). In our study, negative NSPs of FMDV sera were inspected to estimate defensive level of governorate and prevailing local vaccines in addition to FMDV serovars A, O and SAT2 antibody titer. It is sustained by Abd El-Rhman et al., (2015) who verified $60.77 \%$ between immunized cattle and $76.65 \%$ between immunized buffaloes. On the other hand, Shabana (2009) stated immunization in Egypt could defend 63\% of animals, $20 \%$ of animals under risk, and $17 \%$ of animals still subject to infection; this may be because of FMDv serotype SAT2 was officially recorded 2012.

Vaccination is the actual way for disease control and prevent the extent of the disease (Mahapatra and Parida, (2018); Depa et al., (2012)). Consistent immunization of ruminant in contradiction of FMD in Egypt, has become significant effort to continue animal production and to decrease financial costs Knight-Jones et al., (2015), but not inhibit carrier state Ma et al., (2011). The current vaccine is inactivated trivalent FMD vaccine of serotypes (Diab et al., 2019); of antigenic mass 6.5, 6.2, and 5.9, respectively Hussein et al., (2015). To induce the allowed protection in immunized animals, Daoud et al., (2013). Jamal et al., (2013) recorded those low immune replies (low defensive antibody titer) against FMDV by the nearby created vaccines. Defense discussed by the vaccine is serotype- specific (Diab et al., (2019), this disturbs the submission of vaccine in the field (Mahapatra and Parida, (2018); Mahapatra et al., (2016)), This agrees with Diab et al., (2019) and Ahmed et al., (2012) who done phylogenetic analysis for virus strains recovered from cattle in Egypt as well as Valdazo-González et al., (2015) who identified FMDv variety particularly SAT2, which is include 14 topotypes. Depending on the efficiency appraisals, vaccination is providing high herd immunity levels for disease control without extra control measures Knight-Jones et al., (2014).

The ELSA results revealed that serotype $\mathrm{O}$ is the dominant strain during $2018(97.5 \%)$ in cattle. These results agreed with Abd Algayed et al., (2018) stated that serotype $\mathrm{O}$ is the dominant strain during $2017(94.9 \%)$ and serotypes A $(56.8 \%)$ is more prevalent during 2016, while SAT2 had been reported in small percentage; $5.4 \%$ and $4.08 \%$ during 2017 and 2016, respectively. Also, these results agreed with previous Egyptian studies which showed that FMDV O, A, SAT2 serotypes were responsible for 2012 outbreak Salem et al., (2012). Ibrahim, (2015) concluded that the protection subsequent vaccination is similar to that subsequently natural infection, but its length is somewhat shorter. A single immunization of inactivated vaccine will defend against experimental challenge for 3-6 months. The length of immunity is precious by the type of adjuvant, antigenic mass and constancy used in the vaccine formulation.

\section{CONCLUSION}

Our study highpoints current serological situation of FMD in Egypt and it clarify the submission of immunization program in governorates needs to be improved. Additional work is essential to determine the correctness of the current serotype A, O and SAT2 vaccines to defend from the presently isolated viruses. As vaccination does not prevent carrier state especially in buffalo's population vaccination alone is improbable to control the disease. Our studies provide useful information to help monitor the Egyptian field FMDV cases where the vaccination programs are adopted to control the disease using A, O and SAT2 serotype vaccine. Therefore, it is highly recommended to continue the update of vaccine strains to comprise the present circulating serotypes of FMDV with incessant monitoring of the genetic variations in viruses from different locations inside Egypt. Moreover, the co-spread of A, O and SAT2 serotypes and topotypes into Egypt can pose an increased threat of emergence of new variants.

\section{REFERENCES}

1. Abd Algayed, M., Elgendy, E., Hagag, N., Shahin, M. and Ibrahim, M.S. (2018). Molecular characterization of FMD virus during 2016-2017 in Egypt. European Journal of Pharmaceutical and Medical Research; 5(12), 90-99.

2. Abd El-Rhman, M.M., Abo El-Hassan, D.G. and Salem, S.A.H. (2015). Sero survey on current status of foot and mouth disease in some Egyptian governorates, 2013-2015. Egypt. J. Virol., 12(2): 48-56.

3. Abd El-Rhman, M.M., Abo El-Hassan, D.G., Awad, W.S. and Salem, S.A.H. (2020). Serological evaluation for the current epidemic situation of foot and mouth disease among cattle and buffaloes in Egypt, Veterinary World,13(1): 1-9. 
4. Ahmed, H.A., Salem, S.A., Habashi, A.R., Arafa, A.A., Aggour, M.G., Salem, G.H., Gaber, A.S., Selem, O., Abdelkader, S.H., Knowles, N.J., Madi, M., ValdazoGonzalez, B., Wadsworth, J., Hutchings, G.H., Mioulet, V., Hammond, J.M. and King, D.P. (2012). Emergence of foot and mouth disease virus SAT2 in Egypt during 2012. Transbound. Emerg. Dis. 59(6): 476-481.

5. Aktas, M.S., Ozkanlar, Y., Oruc, E., Sozdutmaz, I. and Kirbas, A. (2015). Myocarditis associated with foot and mouth disease in suckling calves. Veterinarski arhiv. 85:273-282.

6. Brocchi, E., Bergmann, I.E., Dekker, A., Paton D.J., Sammin, D.J., Greiner, M., Grazioli, S., De Simone, F., Yadin, H., Haas, B., Bulut, N., Malirat, V., Neitzert, E., Goris, N., Parida, S., Sorensen, K. and De Clercq, K. (2006). Comparative evaluation of six ELISAs for the detection of antibodies to the non-structural proteins of foot-and-mouth disease virus. Vaccine. 24(4748):6966-6979.

7. Clavijo, A., Wright, P. and Kitching, P. (2004). Developments in diagnostic techniques for differentiating infection from vaccination in foot-andmouth disease. Veterinary Journal. 167(1):9-22.

8. Daoud, H.M., Ibrahim, E.E., El-Din, W.M.G. and Hassanin, A.I.H. (2013). Preparation of Foot and Mouth Disease trivalent vaccine type A, O, SAT2 and determination of the Guinea pig protective dose 50 (GPPD50). Vet. World. 6(11): 844-851.

9. Depa, P.M., Dimri, U., Sharma, M.C. and Tiwari, R. (2012). Update on epidemiology and control of foot and mouth disease a menace to international trade and global animal enterprise. Vet. World. 5(11): 694-700.

10. El-Bagoury, G.F.; El-Habbaa, A.S.; Gamil, M.A. and Fawzy, H.G. (2014): Evaluation of an inactivated combined oil vaccine prepared for foot and mouth disease and bovine ephemeral fever. Benha Vet. Med. J., 27(1): 221-231.

11. El Bahgy, H.E.K. and Moustafa, M.M.A. (2018). ELISA, RT-PCR, semi-quantitative RT-PCR and sequencing methods for investigating an epidemic FMD virus serotype O outbreaks. Afr.J. Biotechnol. 17(15): 505-514.

12. El Daous, H.G.A. (2016). Some Epidemiological Studies on Foot and Mouth Disease in Egypt. M.V.Sc. thesis, faculty of Veterinary Medicine, Moshthor, Benha University.

13. Ferris, N., Nordengrahn, A., Hutchings, G., Reid, S., King, D., Ebert, K., Paton, D., Kristersson, T., Brocchi, E., Grazioli, S. and Merza, M. (2009). Development and laboratory validation of a lateral flow device for the detection of foot-and-mouth disease virus in clinical sample. Journal of Virological Methods. 155:10-17.

14. Hiam Fakhry, M. (2005). The use of new developing methods to differentiate between vaccinated and infected cattle by Foot and Mouth Disease virus. Ph.D. Thesis, Fac. Vet. Med. Zagazig University (Benha Branch).

15. Hussein, H.A., Khalil, S.A. and Saad, M.A. (2015). Comparative studies of the potency of foot and mouth disease virus trivalent vaccine with different concentration of the antigenic content (146s). Alex. J. Vet. Sci. 45: 33-42.

16. Ibrahim, E.D.M. (2015). Some Epidemiological Studies on Foot and Mouth Disease (FMD) in Cattle and Buffalo in Egypt. M.V.Sc., Infectious Diseases, faculty of vet. Med. Cairo University.1-146.
17. Jamal, S.M., Shah, S.I., Ali, Q., Mehmood, A., Afzal, M., Afzal, M. and Dekker, A. (2013). Proper quality control of formulated foot and mouth disease vaccines in countries with prophylactic vaccination is necessary. Transbound. Emerg. Dis. 61(6): 483-489.

18. Kitching, R.P. (2002). Identification of foot and mouth disease virus carrier and sub clinically infected animals and differentiation from vaccinated animals. Rev Sci Tech. 21: 531-538.

19. Knight-Jones, T.J.D., Bulut, A.N., Gubbins, S., Stark, K.D., Pfeiffer, D.U., Sumption, K.J. and Paton, D.J. (2015). Randomized field trial to evaluate serological response after foot and mouth disease vaccination in Turkey. Vaccine J. 33(6): 805-811.

20. Knight-Jones, T.J.D., Bulut, A.N., Gubbins, S., Stärk, K.D.C., Pfeiffer, D.U., Sumption, K.J. and Paton, D.J. (2014). Retrospective evaluation of foot and mouth disease vaccine effectiveness in Turkey. Vaccine $\mathrm{J}$. 32(16): 1848-1855.

21. Knowles, N.J., He, J., Shang, Y., Wadsworth, J., Valdazo-González, B. and Onosato, H. (2012). Southeast Asian foot and mouth disease viruses in Eastern Asia. Emerging Infectious Diseases journal. 18:499-501.

22. Lamya A.F.A., Said, A.A., Khamees A.K.S. and Abdel-Hady, H.A. (2017). Evaluation of vaccination with local and imported vaccine against foot and mouth disease virus in Kalubeya governorate. J. of Virol. Sci. 1: 20-26.

23. Ma, L.N., Zhang, J., Chen, H.T., Zhou, J.H., Ding, Y.Z. and Liu, Y.S. (2011). An overview on ELISA techniques for FMD. Virol. J. 8: 419.

24. Mahapatra, M. and Parida, S. (2018). Foot and mouth disease vaccine strain selection: Current approaches and future perspectives. Expert Rev. Vaccin J. 17(7): 577-591.

25. Mahapatra, M., Statham, B., Li, Y., Hammond, J., Paton, D. and Parida, S. (2016). Emergence of antigenic variants within serotype A FMDV in the Middle East with antigenically critical amino acid substitutions. Vaccine J. 34(27): 3199-3206.

26. Mesfine, M., Nigatu, S., Belayneh, N. and Jemberu, W.T. (2019). Sero-epidemiology of foot and mouth disease in domestic ruminants in Amhara Region, Ethiopia. Front. Vet. Sci. 6: 130.

27. OIE. (Office International des Epizooties) (2012). Manual of Diagnostic Tests and Vaccines for Terrestial Animals, $7^{\text {th }}$ ed. (Chapter 2.1.5).

28. Paton, D.J., Sumption, K.J. and Charleston, B. (2009). Options for control of foot and mouth disease: Knowledge, capability and policy. Philos. Trans. R. Soc. Lond. B. Biol. Sci. 364(1530): 2657-2667.

29. Raof, A.M.A., Haleem, I.Y., Aly, N.M., Garhy, M.M. and Hosny, G.A. (2011). Epidemiological diagnosis of foot and mouth disease among cattle in Sharkia and Kafr El-Sheikh governorates. Int. J. Virol., 7(4): 191197.

30. Salem, S.A.H., Arafa, A., Abohatab, E., Saad, A. and Ahmed, H.A. (2012). Genotyping of Foot and Mouth Disease Virus (FMD) in Egypt during 2011-2012. 1st Conf. of An. Health Res. Inst. Assoc. 1: 411-419.

31. Shabana, W.S.O. (2009). Serological Survey for detection of antibodies against different types of FMDV. Master Thesis. Virology Department, Cairo University, Egypt.

32. Sobhy, N.M., Bayoumi, Y.H., Mor, S.K., El-Zahar, H.I. and Goyal, S.M. (2018). Outbreaks of foot and 
mouth disease in Egypt: Molecular epidemiology, evolution and cardiac biomarkers prognostic significance. International Journal of Veterinary Science and Medicine. 6: 22-30.

33. Uttenthal, A., Parida, S., Rasmussen, T.B., Paton, D.J., Haas, B. and Dundon, W.G. (2010). Strategies for differentiating infection in vaccinated animals (DIVA) for foot and mouth disease, classical swine fever and avian influenza. Expert Review of Vaccines. 9:73-87.

34. Valarcher, J.F., Leforban, Y., Rweyemamu, M., Roeder, P.L., Gerbier, G., Mackay, D.K., Sumption, K.J., Paton, D.J. and Knowles, N.J. (2008). Incursions of foot-and-mouth disease virus into Europe between 1985 and 2006.Transbound Emerg. Dis. 55(1):14-34.

35. Valdazo-González, B., Kim, J.T., Soubeyrand, S., Wadsworth, J., Knowles, N.J., Haydon, D. and King, D.P. (2015). The impact of within-herd genetic variation upon inferred transmission trees for foot-andmouth disease virus. Infect. Genet. Evol. 32(1): 440448.

36. Zeedan, G.S.G., Mahmoud, A.H., Abdalhamed, A.M. and Khafagi, M.H. (2020). Diagnosis of Foot and Mouth Disease in cattle and buffaloes in different Governorates of Egypt. World Vet. J. 10 (1): 43-52. 